Recurrent and Resistant Torsade de Pointes Due to Methadone

\title{
Poisoning: A Case Report
}

\author{
Hamidreza Mashreghimoghadam, ${ }^{1}$ Nahid Azdaki, ${ }^{1,}$ and Toba Kazemi ${ }^{1}$ \\ ${ }^{1}$ Birjand Cardiovascular Diseases Research Center, Birjand University of Medical Sciences, Birjand, IR Iran \\ "Corresponding author: Nahid Azdaki, Birjand Cardiovascular Diseases Research Center, Birjand University of Medical Sciences, Birjand, IR Iran. Tel: +98-915125 3431, Fax: \\ +98-563243 0076, E-mail: nahidazdaki@yahoo.com
}

Received 2016 February 20; Revised 2017 March 13; Accepted 2017 April 30.

\begin{abstract}
Introduction: Opiate dependence is among the main contributors to diseases worldwide, imposing heavy costs on the healthcare system. As an established approach, substitution therapy by methadone has been long considered as the most effective therapeutic method.

Case Presentation: Herein, we present the case of a 40-year-old man, who was referred to the hospital with complaints of sudden and transient loss of consciousness and a history of opiate dependence under methadone therapy, showing recurrent ventricular tachycardia and resistant torsade de pointes.

Conclusions: Poisoning is among the major adverse effects of methadone use, which involves different systems of the body, including the cardiovascular and respiratory systems. Furthermore, effective drugs on QT interval show interferences. Therefore, it is suggested to incorporate relevant recommendations in the new version of the national opiate-dependence therapy protocol.
\end{abstract}

Keywords: Methadone Poisoning, Cardiac Arrhythmia, Torsade de Pointes, Therapy

\section{Introduction}

Opiate dependence is among the main contributors to diseases worldwide, imposing heavy financial costs on the healthcare system (1). Considering the importance of applying a proper approach in the treatment of opiate dependence, several medicinal and nonmedicinal methods have been introduced $(2,3)$. Methadone maintenance therapy (MMT) is recognized as the optimal treatment for this disorder, which can both improve the physical symptoms of withdrawal and reduce social consequences, such as HIV transmission and spread (2). Nonetheless, there are ongoing concerns about methadone abuse or poisoning in addicts or their family members $(4,5)$.

The major side-effects of abuse or poisoning by methadone or other opioids include respiratory or cardiovascular complications (6-10). In this regard, strong recommendations have been proposed to examine individuals, who are prone to such conditions prior to methadone therapy, at least via electrocardiography (ECG) $(5,11)$. Cardiac complications caused by methadone poisoning include prolonged QT interval and increased risk of ventricular arrhythmia, especially torsade de pointes (TdP) (11-13). However, occurrence of this type of ventricular arrhythmia, especially the drug-resistant type, has been rarely reported. The present case report introduces a patient with resistant TdP, induced by methadone poisoning.

\section{Case Presentation}

The patient was a 40-year-old man, who was referred to the emergency ward of Vali-Asr Hospital (Birjand, Iran), as the main referral hospital for cases of poisoning (14). He had complaints of sudden and transient loss of consciousness in the sitting position. However, he did not mention any signs of lightheadedness, sweating, or chest pain before the event. Also, he did not report any history of diseases, such as diabetes, hypertension, dyslipidemia, stroke, heart attack, or thyroid dysfunction.

The medical history of the patient only showed a 5-year history of addiction, and withdrawal had started a year before with $5 \mathrm{cc}$ of methadone intake per day. According to the patient's report, he was treated by metoprolol tablets in later visits to the physician. Examination performed by the emergency physician upon admission revealed a blood pressure of $120 / 80 \mathrm{mmHg}$, pulse rate of $60 \mathrm{bpm}$, respiratory rate of $13 \mathrm{bpm}$, body temperature of $37.1^{\circ} \mathrm{C}$, and $\mathrm{O}_{2}$ saturation of $97 \%$. 
Examination of different systems of the body did not show any abnormalities. The patient was referred for cardiac care to monitor ECG changes, including T-wave inversion in the inferior leads and prolonged QT interval (Figure 1). In the initial evaluation, troponin I (TPI) was negative, renal function and electrolyte level were normal, and no disorder was found on ECG. As ordered by the cardiologist, the patient was hospitalized in the cardiac care unit (CCU) for 24-hour monitoring due to ECG abnormalities. Three hours after admission, the patient showed ventricular tachycardia (VT), along with loss of consciousness. He was treated with synchronized shocks at $200 \mathrm{~J}$ and intravenous magnesium sulfate $(2 \mathrm{~g})$. Along with magnesium sulfate, lidocaine infusion at a dose of $2 \mathrm{mg} / \mathrm{kg} / \mathrm{h}$ was initiated because of recurrent and resistant VT (Figure 2).

Within 8 hours, recurrent TdP was reported, which was exacerbated by a drop in heart rate. Because of the patient's resistance to antiarrhythmic drug therapies, overdrive pacing was performed at a rate of $90 \mathrm{bpm}$ to cut the VT (Figure 3). During overdrive pacing, the patient's VT was completely suppressed. After 48 hours, the pacemaker was removed, and the patient was transferred to the cardiology ward, as his heart rate was over $60 \mathrm{bpm}$ and he showed a normal QT interval, a normal sinus rhythm, and nonrecurrence of arrhythmia although the pacemaker was off.

After the patient's condition was stable, the medical history-taking revealed that he had tried to commit suicide by taking $200 \mathrm{cc}$ of methadone syrup, equal to $1000 \mathrm{mg}$ of methadone. Accordingly, he received psychiatric counseling. After 24 hours, he was discharged from the cardiology ward in a good general condition and advised to discontinue methadone treatment and start psychotherapy.

\section{Discussion}

Addiction is associated with not only high rates of mortality and morbidity, but also serious familial, legal, and social consequences. Drug dependence is of notable significance in Iran, with a relatively high prevalence because of the geographical location of the country and neighboring countries, such as Afghanistan (15). Overall, the high incidence of severe health complications from addiction, besides the relative ineffectiveness of abstinence treatments in addiction management, has promoted MMT programs across the country. Domestic and international studies have also shown that MMT programs can control addiction-related damages in patients and reverse the process (16).

The recommended dose for methadone therapy ranges from 60 to $100 \mathrm{mg} /$ day, while higher doses are associated with prolonged QT intervals (13). In recent years, an increase in the dosage of methadone has resulted in the higher frequency of prolonged QT intervals and TdP (13). Our patient had used a very high dose of methadone, which had disrupted the ECG findings. Additionally, the high dose of methadone in our patient explains the occurrence of persistent dysrhythmia.

Numerous extensive studies have been conducted to evaluate the association between methadone dose and prolongation of corrected QT (QTc) interval. A few authors have reported a significant direct relationship and claimed that the risk of QT prolongation increases, as the methadone dose increases (17-20). Nevertheless, some researchers believe that QTC interval prolongation may happen even at therapeutic doses of methadone (21-23).

In this regard, Krantz et al. examined the association between daily doses of methadone and QTc interval in methadone-treated patients with TdP. They noted that daily doses of methadone were positively correlated with QTC interval (17). Moreover, Routhier and colleagues introduced the case of a 52-year-old woman, with no underlying cardiac diseases. She had developed QTc interval prolongation and TdP secondary to high-dose methadone therapy. In their case report, methadone contributed to QTc prolongation and TdP in a dose-dependent manner (18). Walker et al. also reported 3 cases of TdP, receiving daily doses of methadone over $600 \mathrm{mg}$; one patient presented with respiratory distress and two with syncope (19).

Another cause of TdP persistence in our case may be related to the long elimination half-life of methadone. On average, bioavailability of methadone is higher than that of other opioids, and in case of overdose, the elimination halflife is about 65 hours (13). Other risk factors for TdP in the literature include high-dose methadone therapy, HIV infection, female gender, hypokalemia, liver cirrhosis or renal failure, and simultaneous consumption of drugs (such as beta-blockers), which increases the serum methadone concentration.

It should be noted that the latest version of the national opiate-dependence therapy protocol for methadone recommends ECG only for patients with a history of cardiovascular problems, individuals above 50 years, and patients with other risk factors for cardiac arrhythmia. As for the increased risk of prolonged QT interval, recommendations are limited to physical examination (16). Given the high prevalence of methadone poisoning and cardiac complications, changes in the national protocol and ECG examination of all patients undergoing methadone therapy seem necessary $(4,11)$.

Another possibility is that patients taking methadone may use newer drugs and are consequently at risk of dangerous drug interactions whenever using other drugs in combination with methadone (e.g., prolongation of QT interval). In the present case, another reason for the pa- 

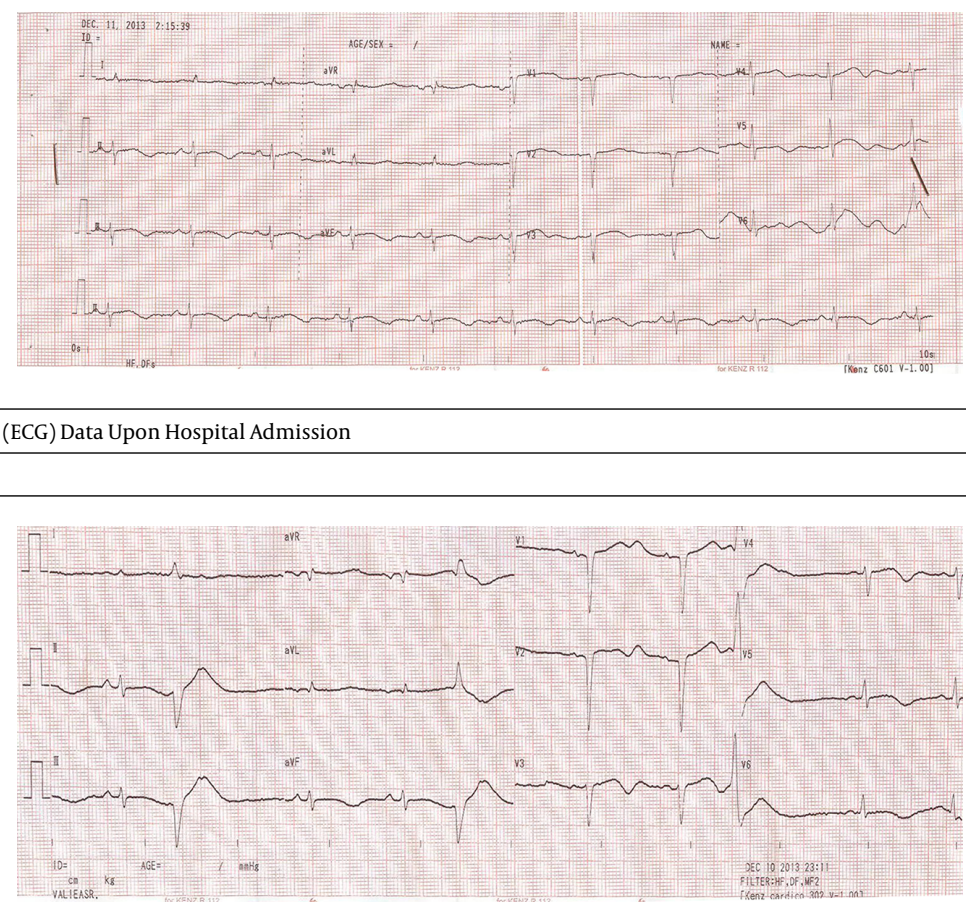

Figure 2. The Electrocardiography (ECG) Data Upon CCU Admission

Figure 3. Torsade de Pointes (TdP)

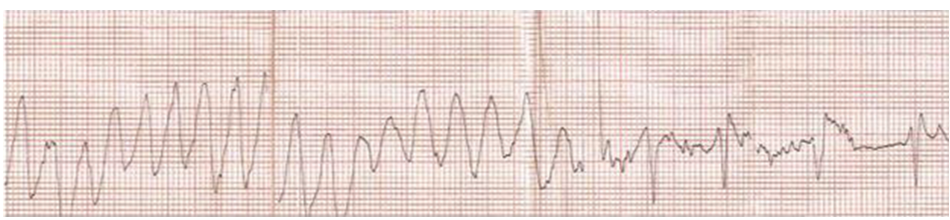

TdP stopped after overdrive pacing.

tient's susceptibility to TdP was the concomitant use of metoprolol as a beta-blocker and methadone. Since the latest version of the opiate-dependence therapy protocol for methadone fails to mention drug interferences leading to increased QT interval (e.g., interactions with betablockers), it is recommended to consider expert comments in this area (16).

\subsection{Conclusions}

Methadone poisoning is among the major adverse effects of methadone use, which involves different systems of the body, including the cardiovascular and respiratory systems. Also, effective medications on QT interval may have interactions with methadone. Therefore, it is suggested to incorporate relevant recommendations in the new version of the national opiate-dependence therapy protocol.

\section{Acknowledgments}

The authors express their gratitude to the cardiovascular research center of Birjand University of Medical Sciences, as well as the authorities of Vali-Asr educational hospital of Birjand, especially the achieves department for their assistance in preparing this report.

\section{References}

1. Degenhardt L, Charlson F, Mathers B, Hall WD, Flaxman AD, Johns N, et al. The global epidemiology and burden of opioid dependence: results from the global burden of disease 2010 study. Addiction. 2014;109(8):1320-33. doi: 10.1111/add.12551. [PubMed: 24661272]. 
2. Larney S, Gowing L, Mattick RP, Farrell M, Hall W, Degenhardt L. A systematic review and meta-analysis of naltrexone implants for the treatment of opioid dependence. Drug Alcohol Rev. 2014;33(2):115-28. doi:10.1111/dar.12095. [PubMed: 24299657].

3. Dennis BB, Naji L, Bawor M, Bonner A, Varenbut M, Daiter J, et al. The effectiveness of opioid substitution treatments for patients with opioid dependence: a systematic review and multiple treatment comparison protocol. Syst Rev. 2014;3:105. doi: 10.1186/2046-4053-3-105. [PubMed: 25239213].

4. Navabi SJ, Iranmanesh AA, Navabi SM, Iranmanesh A, Aghaei A, Iranmanesh AH. Methadone toxicity in a poisoning referral center. Int Sci Investigati J. 2015;4(1):78-82.

5. Pilgrim JL, McDonough $\mathrm{M}$, Drummer $\mathrm{OH}$. A review of methadone deaths between 2001 and 2005 in Victoria, Australia. Forensic Sci Int. 2013;226(1-3):216-22. doi: 10.1016/j.forsciint.2013.01.028. [PubMed: 23419969].

6. Moradi M, Ghaemi K, Mehrpour O. A hospital base epidemiology and pattern of acute adult poisoning across Iran: a systematic review. Electron Physician. 2016;8(9):2860-70. doi: 10.19082/2860. [PubMed: 27790337].

7. Ghaderi A, Vahdati-Mashhadian N, Oghabian Z, Moradi V, Afshari R, Mehrpour O. Thallium exists in opioid poisoned patients. Daru. 2015;23:39. doi: 10.1186/s40199-015-0121-x. [PubMed: 26231176].

8. Hashemian AM, Omraninava A, Kakhki AD, Sharifi MD, Ahmadi K, Masoumi B, et al. Effectiveness of local anesthesia with lidocaine in chronic opium abusers. J Emerg Trauma Shock. 2014;7(4):301-4. doi: 10.4103/0974-2700.142765. [PubMed: 25400392].

9. Mehrpour O, Sezavar SV. Diagnostic imaging in body packers. Mayo Clin Proc. 2012;87(7):e53-4. doi: 10.1016/j.mayocp.2012.03.014. [PubMed: 22766092].

10. Mehrpour O. Addiction and seizure ability of tramadol in highrisk patients. Indian J Anaesth. 2013;57(1):86-7. doi: 10.4103/00195049.108584. [PubMed: 23716779].

11. Chou R, Cruciani RA, Fiellin DA, Compton P, Farrar JT, Haigney MC, et al. Methadone safety: a clinical practice guideline from the American Pain Society and College on Problems of Drug Dependence, in collaboration with the Heart Rhythm Society. J Pain. 2014;15(4):321-37. doi: 10.1016/j.jpain.2014.01.494. [PubMed: 24685458].

12. Khalesi S, Shemirani H, Dehghani-Tafti F. Methadone induced torsades de pointes and ventricular fibrillation: A case review. ARYA Atheroscler. 2014;10(6):339-42. [PubMed: 25815024].
13. Alinejad S, Kazemi T, Zamani N, Hoffman RS, Mehrpour O. A systematic review of the cardiotoxicity of methadone. EXCLI J. 2015;14:577600. doi: 10.17179/excli2015-553. [PubMed: 26869865].

14. Mehrpour O, Abdollahi M. Poison treatment centers in Iran. Hum Exp Toxicol. 2012;31(3):303-4. doi: 10.1177/0960327110392086. [PubMed: 21138986].

15. Karrari P, Mehrpour O, Afshari R, Keyler D. Pattern of illicit drug use in patients referred to addiction treatment centres in Birjand, Eastern Iran.J Pak Med Assoc. 2013;63(6):711-6. [PubMed: 23901670].

16. Alinejad S, Ghaemi K, Abdollahi M, Mehrpour O. Nephrotoxicity of methadone: a systematic review. Springerplus. 2016;5(1):2087. doi: 10.1186/s40064-016-3757-1. [PubMed: 28018795].

17. Krantz MJ, Kutinsky IB, Robertson AD, Mehler PS. Dose-related effects of methadone on QT prolongation in a series of patients with torsade de pointes. Pharmacotherapy. 2003;23(6):802-5. [PubMed:12820821].

18. Routhier DD, Katz KD, Brooks DE. QTc prolongation and torsades de pointes associated with methadone therapy. J Emerg Med. 2007;32(3):275-8. doi: 10.1016/j.jemermed.2006.07.027. [PubMed: 17394991].

19. Walker PW, Klein D, Kasza L. High dose methadone and ventricular arrhythmias: a report of three cases. Pain. 2003;103(3):321-4. [PubMed: 12791438].

20. Ehret GB, Voide C, Gex-Fabry M, Chabert J, Shah D, Broers B, et al Drug-induced long QT syndrome in injection drug users receiving methadone: high frequency in hospitalized patients and risk factors. Arch Intern Med. 2006;166(12):1280-7. doi: 10.1001/archinte.166.12.1280. [PubMed: 16801510].

21. Krantz MJ, Lowery CM, Martell BA, Gourevitch MN, Arnsten JH. Effects of methadone on QT-interval dispersion. Pharmacotherapy. 2005;25(11):1523-9. doi: 10.1592/phco.2005.25.11.1523. [PubMed 16232014].

22. Maremmani I, Pacini M, Cesaroni C, Lovrecic M, Perugi G, Tagliamonte A. QTc interval prolongation in patients on long-term methadone maintenance therapy. Eur Addict Res. 2005;11(1):44-9. doi: 10.1159/000081416. [PubMed: 15608471].

23. Peles E, Bodner G, Kreek MJ, Rados V, Adelson M. Corrected-QT intervals as related to methadone dose and serum level in methadone maintenance treatment (MMT) patients: a cross-sectional study. Addiction. 2007;102(2):289-300. doi: 10.1111/j.1360-0443.2006.01668.x. [PubMed: 17222284]. 